\title{
Aflatoxin and Bright Greenish-Yellow Fluorescence of Corn Kernels Inoculated with Aspergillus Flavus Genotypes (rflp) from a Field in Illinois
}

\author{
D. T. Wicklow
}

\begin{abstract}
The objective of this study was to relate the diversity of a naturally occurring population of Aspergillus flavus to their ability to contaminate the grain with aflatoxin and produce bright greenish- yellow fluorescent (BGYF) kernels. Nineteen strains of $A$. flavus isolated from a corn field near Kilbourne, Illinois were used as inoculum, including 16 genotypes (DNA fingerprinting), and representing both aflatoxin producers and non-producers. A commercial corn hybrid (Pioneer 3394) was grown in this field in 1996 and 1998 and twenty ears in the late milk to early dough stage of maturity were inoculated with each $A$. flavus strain using a toothpick wound procedure. At harvest, 20-24 kernels nearest each wounded site were separated into three categories: wound-inoculated kernels, intact BGYF kernels, and all other intact kernels. Sample weights of intact BGYF kernels in 1996 and 1998 grain samples averaged $5.0 \%$ and $9.5 \%$ of the total sample weight, respectively. Aflatoxin producing strains were associated with a higher frequency $(\mathrm{P}<0.05)$ of BGYF kernels for grain samples harvested in 1998. Removal of the individual wound-inoculated kernels and the intact BGYF kernels from corn ears inoculated with 13 aflatoxin-producing strains of $A$. flavus, lowered mean aflatoxin values from $115 \mathrm{ng} / \mathrm{g}$ (range $=<1$ to $387 \mathrm{ng} / \mathrm{g}$ ) to $2 \mathrm{ng} / \mathrm{g}$ for 1996 grain samples and from $744 \mathrm{ng} / \mathrm{g}$ (range $=20$ to $1416 \mathrm{ng} / \mathrm{g}$ ) to $33 \mathrm{ng} / \mathrm{g}$ for 1998 grain samples. Results indicated substantial variation among $A$. flavus genotypes in their ability to produce aflatoxin in the germ and endosperm of infected BGYF kernels. The naturally occurring $A$. flavus population may include a majority of strains that produce no aflatoxin but exhibit BGYF and are thus aflatoxin "false positives" when corn grain is examined with an ultra violet light at $365 \mathrm{~nm}$. Intraspecfic competition between aflatoxin producing and non-producing strains would be expected to naturally suppress the severity of aflatoxin outbreaks within the Midwestern corn belt.
\end{abstract}

Key words: aflatoxin, Aspergillus flavus, bright greenish-yellow fluorescence, corn, genotype.

\section{Introduction}

The corn industry's first level of assessment for aflatoxin is the black light test for kernels exhibiting bright greenish-yellow fluorescent (BGYF) kernels. ${ }^{1)}$ The fluorescence is produced by the oxidative action of heat-labile enzymes (peroxidases) in living plant tissue

United States Department of Agriculture, Agricultural Research Service, National Center for Agricultural Utilization Research, Peoria, Illinois, USA

D. T. Wicklow, FAX 309-681-6686 
on kojic acid, which is formed with aflatoxin by Aspergillus flavus Link : Fr. ${ }^{2}$ The detection of BGYF in undamaged kernels is evidence that $A$. flavus has infected the germ and/or endosperm. However, predicting aflatoxin levels is difficult based on the proportion of BGYF kernels or kernel fragments in grain samples. ${ }^{3,4)}$ One reason for this is that kernels infected with $A$. flavus strains that produce kojic acid but do not produce aflatoxin exhibit BGYF and thus are aflatoxin "false positives" when corn grain is examined with a black light. Quantities of aflatoxins are greater when $A$. flavus grows saprotrophically in damaged kernel tissues than when the germ and endosperm of intact kernels are infected. ${ }^{5,6)}$ Aflatoxin concentrations in wound-inoculated corn kernels grown in the University of Wisconsin Biotron ranged from 13,200 to $82,000 \mathrm{ng} / \mathrm{g}$ (mean, $36,700 \mathrm{ng} / \mathrm{g}$ ), while the sample means for intact kernels surrounding each wound site did not exceed 2,100 ng/g $(=2,100 \mathrm{ppb})$ and concentration ranged from 154 to $6290 \mathrm{ng} / \mathrm{g}$. ${ }^{7} \quad$ Unfortunately, no attempt was made to separate BGYF kernels or to record aflatoxin concentration in these kernels. Aspergillus flavus isolates from corn harvested at the University of Illinois River Valley Sand Field (IRVSF, Kilbourne, IL) were characterized recently using DNA fingerprinting and the ability to produce aflatoxin in laboratory culture. ${ }^{8)} \quad$ Naturally occurring populations of $A$. flavus may vary in their pathogenicity/virulence ${ }^{9)}$ and their ability to produce aflatoxin. ${ }^{10)}$ The objective of this study was to determine whether the naturally occurring diversity in this collection of $A$. flavus isolates from Illinois corn is related to their ability to produce BGYF kernels and aflatoxin following wound-inoculation.

\section{Materials and Methods}

The 19 A. flavus strains examined in this study, isolated from corn sampled at harvest at IRVSF, included 16 distinct genotypes (Table 1) and were selected to represent strains that produce or do not produce aflatoxin respectively. ${ }^{8)}$ In 1996 and 1998, a commercial corn hybrid (Pioneer 3394) was grown to maturity at IRVSF. Twenty corn ears in the late-milk to early-dough stage of kernel maturity (about 21 days after mid-silk; 7, August $1996 ; 24$, July 1998) were toothpick wound-inoculated with a conidial suspension of one of the $A$. flavus strains. Ears at 15.5\% moisture content were hand harvested on 2, October 1996 and 19, October 1998. Twenty kernels nearest to each wound site ${ }^{7)}$ were separated into three categories as follows: wound-damaged kernels, intact BGYF kernels as determined with an ultra violet light at $365 \mathrm{~nm}$; and the remaining kernels. Each category of kernels was pooled within each $A$. flavus strain, weighed (see Table 1), ground using a Stein Mill (Steinlite Inc., Atchison, KS), and analyzed for aflatoxins by the Aflatest (Vicam Inc. Watertown, MA) procedure according to the manufacturer's instructions. Calculation of "total sample" aflatoxin levels for each inoculation treatment were performed using the formula: ['wounded kernels' $(\mathrm{g}) \mathrm{x}$ aflatoxin (ng/g) + 'intact BGYF kernels' $(\mathrm{g}) \mathrm{x}$ aflatoxin $(\mathrm{ng} / \mathrm{g})$ + 'all other kernels' (g)x aflatoxin (ng/g) / 'total sample weight' (g)]. A Student's t test was applied at a $5 \%$ or $1 \%$ level of probability to compare the following sample means : \% weight of BGYF kernels for $A$. flavus strains that produce aflatoxin $(\mathrm{n}=13)$ and those that do not $(n=6)$; aflatoxin $(n g / g)$ content of grain samples for $A$. flavus strains that produce aflatoxin harvested in $1996(\mathrm{n}=13)$ and $1998(\mathrm{n}=13)$; aflatoxin $(\mathrm{ng} / \mathrm{g})$ content of grain samples $(\mathrm{n}=13)$ before and after the removal of both the 'wounded kernels' and the 'intact BGYF kernels'. 


\section{Results and Discussion}

In 1996, kernels that were wound-inoculated with one of $19 \mathrm{~A}$. flavus strains and intact BGYF kernels comprised 0.4 to $1.0 \%$ (mean, $0.6 \%$ ) and 1.5 to $11.5 \%$ (mean, $5.0 \%$ ) of the total sample based on weight, respectively (Table 1). In 1998, wound-inoculated and intact BGYF kernels comprised 0.1 to $0.4 \%$ (mean, $0.3 \%$ ) and 2.6 to $14.8 \%$ (mean, $9.5 \%$ ) of the total sample, respectively, based on weight. The ability of $A$. flavus strains to produce aflatoxin was associated with a significantly greater frequency of BGYF kernels (as determined by sample weight) for grain samples harvested in $1998(\mathrm{P}<0.05)$, but not for grain samples harvested in 1996 ( $P>0.05)$. The number of intact BGYF kernels may be associated with frequency of seed coat tearing. A. flavus colonizes the wound-inoculated kernels and uses them as a food base from which to spread and infect the surrounding intact kernels. ${ }^{6,711,12,13)} \quad Z_{u b e r^{14)}}$ and others have observed that $A$. flavus is a weak pathogen of maize and that infection of the grain usually requires a break in the pericarp. ${ }^{15,16)}$ However, the fungus can easily enter the air spaces of the pericarp but cannot infect the germ or endosperm unless a break occurs in the internal seed coat or testa. ${ }^{17)}$ Smart et al. ${ }^{17)}$ showed that $A$. flavus gains entry to the germ through random microscopic breaks in the testa when the surrounding pericarp was intact. Aflatoxin is produced after the fungus invades the embryo or endosperm. The

Table 1 Aflatoxin contamination of corn kenels (Pioneer 3394) would-inoculated with 19 strains of Aspergillus flavus isolated from corn.

Grain at harvest-1996

\begin{tabular}{|c|c|c|c|c|c|c|}
\hline \multirow{3}{*}{$\begin{array}{l}\text { NRRL } \\
\text { No. }\end{array}$} & \multicolumn{2}{|c|}{ Sample weight \% } & \multicolumn{4}{|c|}{ Aflatoxin (ng/g) } \\
\hline & \multirow{2}{*}{$\begin{array}{l}\text { Wounded } \\
\text { kernels }\end{array}$} & \multirow{2}{*}{$\begin{array}{l}\text { Intact } \\
\text { BGYF }\end{array}$} & \multirow{2}{*}{$\begin{array}{l}\text { Wounded } \\
\text { kernels }\end{array}$} & \multicolumn{2}{|c|}{ Intact kernels } & \multirow{2}{*}{$\begin{array}{l}\text { Total } \\
\text { sample }\end{array}$} \\
\hline & & & & BGYF & All other & \\
\hline A-27837 & 0.8 & 2.8 & 13,600 & 3,800 & 3 & 215 \\
\hline 26474 & 0.9 & 7.8 & 16,600 & 2,900 & 14 & 387 \\
\hline 27473 & 0.5 & 6.6 & 12,200 & 1,500 & $<1$ & 164 \\
\hline $26491^{x}$ & 0.5 & 3.0 & 10,800 & 1,200 & 4 & 93 \\
\hline 26482 & 0.4 & 4.9 & 14,800 & 1,100 & 3 & 113 \\
\hline 26468 & 0.9 & 8.0 & 13,000 & 900 & 1 & 191 \\
\hline 26480 & 0.6 & 2.9 & 17,200 & 200 & $<1$ & 108 \\
\hline $26485^{x}$ & 0.4 & 3.1 & 6,000 & 300 & $<1$ & 40 \\
\hline A-27676 & 0.5 & 3.9 & 8,800 & 52 & $<1$ & 45 \\
\hline 26477 & 1.0 & 1.5 & 2,000 & 71 & 0 & 21 \\
\hline $26476^{y}$ & 0.4 & 4.4 & 1,060 & 67 & 0 & 7 \\
\hline $26479^{y}$ & 0.5 & 4.5 & 2 & 0 & 0 & $<1$ \\
\hline 26472 & 0.6 & 4.4 & 280 & 0 & 0 & 2 \\
\hline $26641^{*}$ & 0.6 & 7.4 & 102 & 1 & 0 & $<1$ \\
\hline $26639^{*}$ & 0.6 & 6.2 & 240 & 4 & 0 & 2 \\
\hline A-27675* & 1.0 & 11.5 & 0 & 0 & 0 & 0 \\
\hline $26640^{*}$ & 1.0 & 5.3 & 3 & 0 & 0 & $<1$ \\
\hline A-27667*z & 0.4 & 2.6 & 4 & 3 & 3 & $<1$ \\
\hline A- $27668^{* z}$ & 0.4 & 4.3 & 6 & 0 & $<1$ & $<1$ \\
\hline
\end{tabular}

${ }^{*}$ aflatoxin negative $(-)$ on GYES medium as determined by TLC.

${ }^{\mathrm{xyz}}$ NRRL strains sharing a common genotype. 
Table 2 Aflatoxin contamination of corn kenels (Pioneer 3394) would-inoculated with 19 strains of Aspergillus flavus isolated from corn.

Grain at harvest-1996

\begin{tabular}{|c|c|c|c|c|c|c|}
\hline \multirow{3}{*}{$\begin{array}{l}\text { NRRL } \\
\text { No. }\end{array}$} & \multicolumn{2}{|c|}{ Sample weight \% } & \multicolumn{4}{|c|}{ Aflatoxin (ng/g) } \\
\hline & \multirow{2}{*}{$\begin{array}{l}\text { Wounded } \\
\text { kernels }\end{array}$} & \multirow{2}{*}{$\begin{array}{l}\text { Intact } \\
\text { BGYF }\end{array}$} & \multirow{2}{*}{$\begin{array}{c}\text { Wounded } \\
\text { kernels }\end{array}$} & \multicolumn{2}{|c|}{ Intact kernels } & \multirow{2}{*}{$\begin{array}{l}\text { Total } \\
\text { sample }\end{array}$} \\
\hline & & & & BGYF & All other & \\
\hline A-27837 & 0.3 & 11.0 & 2,200 & 6,400 & 43 & 747 \\
\hline 26474 & 0.4 & 10.8 & 1,800 & 8,700 & 19 & 965 \\
\hline 27473 & 0.2 & 14.8 & 2,000 & 9,200 & 7 & 1,370 \\
\hline $26491^{x}$ & 0.3 & 12.0 & 2,100 & 5,200 & 5 & 634 \\
\hline 26482 & 0.3 & 13.5 & 3,300 & 9,200 & 190 & 1,416 \\
\hline 26468 & 0.4 & 13.7 & 1,400 & 9,200 & 12 & 1,283 \\
\hline 26480 & 0.2 & 13.3 & 1,700 & 7,200 & 36 & 990 \\
\hline $26485^{x}$ & 0.3 & 9.6 & 4,200 & 8,900 & 42 & 904 \\
\hline A- 27676 & 0.1 & 4.8 & 1,100 & 150 & 12 & 20 \\
\hline 26477 & 0.2 & 10.2 & 160 & 610 & 1 & 64 \\
\hline $26476^{y}$ & 0.3 & 10.8 & 620 & 1,840 & 14 & 212 \\
\hline $26479^{y}$ & 0.1 & 6.5 & 0 & 990 & 2 & 66 \\
\hline 26472 & 0.4 & 5.6 & 4,400 & 4,200 & 9.4 & 262 \\
\hline $26641^{*}$ & 0.2 & 9.0 & 0 & $<1$ & 1.7 & 2 \\
\hline $26639^{*}$ & 0.3 & 7.9 & $<1$ & 90 & 5.5 & 12 \\
\hline A-27675* & 0.4 & 9.5 & 0 & 0 & 0 & 0 \\
\hline $26640^{*}$ & 0.2 & 8.8 & 0 & 0 & 4.2 & 4 \\
\hline A-27667 ${ }^{* z}$ & 0.3 & 2.6 & 310 & 86 & 0.1 & 3 \\
\hline A-27668 ${ }^{* z}$ & 0.2 & 6.4 & 0 & 42 & 0 & 3 \\
\hline
\end{tabular}

scattered distribution of undamaged BGYF kernels removed from the same ear ${ }^{12,18,19)}$ may simply mirror the distribution of kernels having torn seed coats. ${ }^{17)}$

Aflatoxin levels for wound-damaged kernels inoculated with one of the 13 aflatoxin producing A. flavus strains exceeded $1000 \mathrm{ng} / \mathrm{g}$ for 11 samples in 1996 and 10 samples in 1998 (Table 1). These light-weight, wound-damaged and shriveled, kernels did not exceed $1 \%$ of the total sample weight for grain harvested from any inoculation treatment or year. Aflatoxin levels for samples of intact BGYF kernels infected with one of the 13 aflatoxin positive strains varied from 0 to $3,800 \mathrm{ng} / \mathrm{g}$ in 1996 and from 150 to $9,200 \mathrm{ng} / \mathrm{g}$ in 1998 . The 1998 values proved to be significantly higher $(\mathrm{P}<.01)$. When the aflatoxin content of each fraction was combined as the weighted mean for each of the treatments inoculated with one of the 13 aflatoxin positive strains, ten grain samples harvested in 1996 and thirteen grain samples harvested in 1998 had unacceptable aflatoxin concentrations $(>20 \mathrm{ng} / \mathrm{g})$. The removal of individual wound-inoculated kernels and intact BGYF kernels from grain samples harvested in 1996 and 1998, resulted in a significant $(\mathrm{P}<.01)$ reduction of the mean aflatoxin values from 115 to $2 \mathrm{ng} / \mathrm{g}$, and from 744 to $33 \mathrm{ng} / \mathrm{g}$, respectively.

Differences in aflatoxin levels and the frequency of BGYF kernels between years, may be explained by differences in the average daily temperatures recorded at IRVSF for September 1996 (16.6 C) and September 1998 (20.6 C), the warmer temperatures favoring $A$. flavus parasitic ability and aflatoxin production. ${ }^{18,20)}$ The extent to which a corn hybrid develops symptoms of $A$. flavus kernel rot and aflatoxin accumulates within individual infected kernels is positively related to temperature during the period of grain filling and 
maturation ${ }^{20)}$ and drought stress. ${ }^{21)}$ The present results show that BGYF kernels become contaminated with different amounts of aflatoxin because $A$. flavus strains differ in their basic ability to produce aflatoxins. Both aflatoxin-positive and aflatoxin-negative strains produced BGYF kernels. The naturally occurring $A$. flavus population may include a majority of strains that produce no aflatoxin ${ }^{8,22)}$ but exhibit BGYF and are thus aflatoxin "false positives" when corn grain is examined with an ultra violet light at $365 \mathrm{~nm}$.

\section{Conclusions}

Interpretations of the association between weight of BGYF kernels and aflatoxin levels in grain samples ${ }^{3)}$ should recognize the aflatoxin producing potential of the $A$. flavus population in regions where corn is grown. Intraspecfic competition between aflatoxin producing and non-producing strains would be expected to naturally suppress the severity of aflatoxin outbreaks within the Midwestern corn belt.

\section{References}

1) Shotwell, O. L., and Hesseltine, C. W. (1981) Use of bright greenish yellow fluorescence as a presumptive test for aflatoxin in corn. Cereal Chem. 58, 124-127.

2) Marsh, P. B. Simpson, M. E., Ferretti, R. J., Merola, G. V., Donoso, J., Craig, G. O., Trucksess, M. W., and Work, P. S. (1969) Mechanism of formation of a fluorescence in cotton fiber associated with aflatoxin in the seeds at harvest. J. Agr. Food Chem. 17, 468-472.

3) Dickens, J. W., and Whitaker, T. B. (1981) Bright greenish-yellow fluorescence and aflatoxin in recently harvested yellow corn marketed in North Carolina. J. Am. Oil Chem. Soc. 58, 973A-975A.

4) Kwolek, W. F., and Shotwell, O. L. (1979) Aflatoxin in white corn under loan. V. Aflatoxin prediction from weight percent of bright greenish-yellow particles. Cereal Chem. 56, 342-345.

5) Scott, G. E, Zummo, N., Lillejoj, E. B., Widstrom, N. W., Kang, M. S., West, D. R., Payne, G. A., Cleveland, T. E., Calvert, O. H., and Fortnum, B. A. (1991) Aflatoxin in corn hybrids field inoculated with Aspergillus flavus. J. of Agron. 83, 595-598.

6) Wicklow, D. T. , Horn, B. W., Shotwell, O. L., Hesseltine, C. W., and Caldwell, R. W. (1988) Fungal interference with Aspergillus flavus infection and aflatoxin contamination of maize grown in a controlled environment. Phytopathology 78, 68-74.

7) Wicklow, D. T., Horn, B. W., and Shotwell, O. L. (1987) Aflatoxin formation in preharvest maize ears co-inoculated with Aspergillus flavus and Aspergillus niger. Mycologia 79, 679-682.

8) Wicklow, D. T., McAlpin, C. E., and Platis, C. E. (1998) Characterization of the Aspergillus flavus population within an Illinois corn field. Mycological Research 102, 263-268.

9) Cotty, P. J. (1989) Virulence and cultural characteristics of two Aspergillus flavus strains pathogenic on cotton. Phytopathology 79, 808-814.

10) Bayman, P., and Cotty, P. J. (1993) Genetic diversity in Aspergillus flavas: association with aflatoxin production and morphology. Can. J. Bot. 71, 23-31.

11) King. D. B., and Scott, G. E. (1982) Field inoculation techniques to evaluate maize for reaction to kernel infection by Aspergillus flavus. Phytopathology 72, 782-785.

12) Smart, M. L., Shotwell, O. L., and Caldwell, R. W. (1990a) Pathogenesis in Aspergillus ear rot of maize: Aflatoxin B1 levels in grains around wound-inoculation sites. Phytopathology 80, 1283-1286.

13) Zummo, N., and Scott, G. E. (1989) Evaluation of field inoculation techniques for screening maize genotypes against kernel infection by Aspergillus flavus in Mississippi. Plant Dis. 73, 313-316.

14) Zuber, M. S. (1977) Influence of plant genetics on toxin production in corn. In Rodricks, J. V., Hesseltine, C. W. and Mehlman, M. A. (eds.), Mycotoxins in Human and Animal Health. Pathotox Publishers, Park Forest South, Illinois.

15) Guo, B. Z., Russin, J. S., Cleveland, T. E., Brown, R. L., and Widstrom, N. W. (1993) The role of the 
pericarp of corn kernels to reduce infection and aflatoxin production by Aspergillus flavus. Phytopathology 83, 1417-1418.

16) Koehler, B. (1957) Pericarp injuries in seed corn. Prevalence in dent corn and relation to seedling blights. University ofIllinois Agricultural Experiment Station. Bulletin 617, Urbana, IL

17) Smart, M. J., Wicklow, D. T., and Caldwell, R. W. (1990b) Pathogenesis in Aspergillus ear rot of maize: light microscopy of fungal spread from wounds. Phytopathology 80, 1287-1294.

18) Jones, R. K., Duncan, H. E., Payne, G. A., and Leonard, K. J. (1980) Factors influencing infection by Aspergillus flavus in silk-inoculated corn. Plant Dis. 64, 859-863.

19) Lee, L. S., Lillehoj, E. B., and Kwolek, W. F. (1980) Aflatoxin distribution in individual corn kernels from intact ears. Cereal Chem. 57, 340-343.

20) Wicklow, D. T. (1994) Preharvest origins of toxigenic fungi in stored grain. In Highley, E., Wright, E. J., Banks, H. J. and Champ, B. R. (eds.), Stored Product Protection. CAB International, Wallingford, England.

21) Payne, G. A., Cassel, D. K., and Adkins, C. R. (1986) Reduction in aflatoxin contamination in corn due to irrigation and tillage. Phytopathology 76, 679-684.

22) Shearer, J. F., Sweets, L. E., Baker, N. K. and Tiffany, L. H. (1992) A study of Aspergillus flavus/ parasiticus in lowa crop fields : 1988-1990. Plant Disease 76, 19-22. 